\title{
Investigation of suitable sites for wave energy converters around Sicily (Italy)
}

\author{
C. Iuppa ${ }^{1}$, L. Cavallaro ${ }^{1}$, D. Vicinanza ${ }^{2}$, and E. Foti ${ }^{1}$ \\ ${ }^{1}$ Department of Civil Engineering and Architecture, University of Catania Via Santa Sofia 64, 95123 Catania, Italy \\ ${ }^{2}$ Department of Civil Engineering, Design, Building and Environment, Second University of Naples, Via Roma 29, \\ 81031 Aversa, Caserta, Italy
}

Correspondence to: C. Iuppa (ciuppa@dica.unict.it)

Received: 02 February 2015 - Published in Ocean Sci. Discuss.: 20 February 2015

Revised: 25 May 2015 - Accepted: 13 June 2015 - Published: 09 July 2015

\begin{abstract}
An analysis of wave energy along the coasts of Sicily (Italy) is presented with the aim of selecting possible sites for the implementation of wave energy converters (WECs). The analysis focuses on the selection of hotspot areas of energy concentration. A third-generation model was adopted to reconstruct the wave data along the coast over a period of 14 years. The reconstruction was performed using the wave and wind data from the European Centre for Medium-Range Weather Forecasts. The analysis of wave energy allowed us to characterise the most energetic zones, which are located on the western side of Sicily and on the Strait of Sicily. Moreover, the estimate of the annual wave power on the entire computational domain identified eight interesting sites. The main features of the sites include relatively high wave energy and proximity to the coast, which makes them possible sites for the implementation of WEC farms.
\end{abstract}

\section{Introduction}

Currently, renewable energy supplies $20 \%$ of the total world's energy demand, and this percentage continues to grow (IEA, 2014). Among various sources, wave energy has attracted the attention of the scientific community and the energy industry from 1973 due to its numerous advantages such as (i) greater high energy density than solar and wind energy (Falnes, 2007); (ii) the ability to reliably predict waves; (iii) wave energy travels with small losses in depth water; and (iv) minimal environmental impacts, especially for the offshore devices. Due to these advantages, wave energy con- verters (WECs) will likely become diffuse in the near future, thus impacting the further transformation of our coastal zones (Azzellino et al., 2013a, b). However, the costs to implement WECs are currently much higher than those of other renewable energy technologies. Therefore, a solution to reduce such costs is to move from stand-alone devices to hybrid systems embedded in other coastal or offshore structures (Kallesøe et al., 2009; Vicinanza et al., 2014). Today, more than 1000 WECs have been patented and approximately 170 companies are working to improve WEC technology (for a detailed description see www.emec.org.uk). An analysis of the location of these companies shows that $50 \%$ are located in Europe. This is primarily due to the high amount of the wave energy that characterises the north and west sides of European coast. For example, in Galicia, the region in the NW of Iberia, the offshore wave power is approximately $22 \mathrm{~kW} \mathrm{~m}^{-1}$ (Iglesias and Carballo, 2010a).

As shown in Fig. 1, waves around Italy have a relatively low energy. However, previous studies have shown that wave farms could be implemented at some sites. For example, Vicinanza et al. (2011) reported the offshore wave energy potentials of the Italian seas. This study was carried out using records from the buoys of the Italian National Wave Recording Network (NWRN), managed by the Agency for Environmental Protection and Technical Services. The results highlighted that the west coasts of both Sardinia and Sicily are the most energetic among the Italian coasts. Indeed, the highest energy values were obtained for the buoys of Alghero and Mazara del Vallo, which corresponded to 9.05 and $4.75 \mathrm{~kW} \mathrm{~m}^{-1}$, respectively. In addition, Liberti et al. (2013) presented a high-resolution assessment of the wave energy 


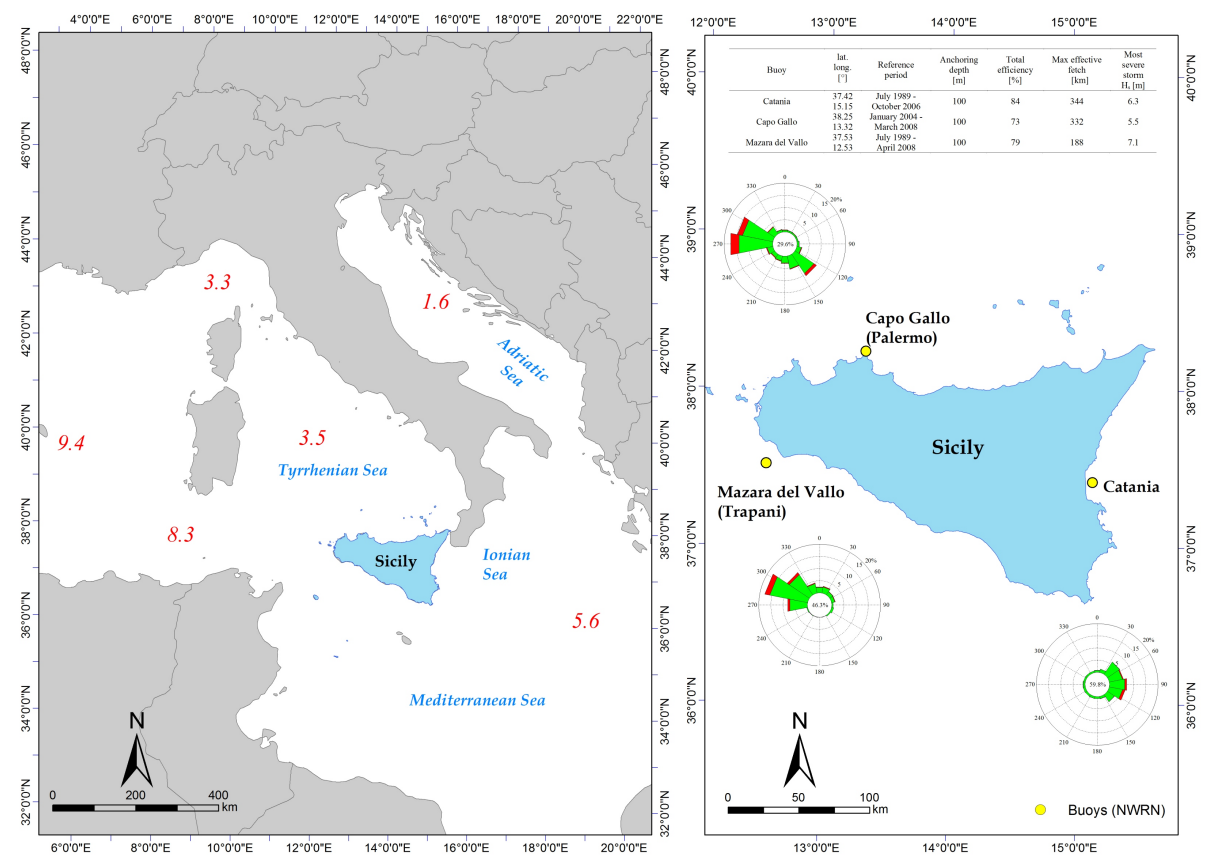

Figure 1. Location of study area. The red values in the left picture indicate the yearly mean wave power flux (in $\mathrm{kW} \mathrm{m}^{-1}$ ) estimates by ECMWF data.

resources in the Mediterranean Sea. In particular, a thirdgeneration model of the ocean waves was used to derive the wave climate over the entire Mediterranean Basin consistently with results of Vicinanza et al. (2011).

The study of potential wave energy is important for selecting and designing WECs. It is necessary to understand how the energy is distributed with respect to wave height, period and direction. An appropriate wave climate analysis will reveal the best configuration of device and location to be selected. However, to this aim, a long period (not less than 10 years) of wave data is necessary. In general, it is better to utilise wave data gathered by buoys, as the data are of good quality with a low relative error. However, the Italian buoys are characterized by periods of lack of records. For this reason, it is useful to use data delivered by forecast centres, such as those of the European Centre for Medium-Range Weather Forecasts (ECMWF) or of the National Oceanic and Atmospheric Administration (NOAA). The data from these sources have high spatial and temporal resolution but underestimate peak events (Cavaleri, 2009). However, the nearshore wave data from these sources may not be used because the wave propagation was performed using the WAM (Hasselmann et al., 1988) or WAVEWATCH III (Tolman and Chalikov, 1996) models, which do not consider the phenomena as triad interactions. Moreover, the grid resolution of the wave model is too large to select suitable sites for locating wave energy converters; therefore, it is necessary to use advanced numerical codes that allow the wave propagation in intermediate-depth and shallow waters to be appropriately modelled. The use of such a model allows for the selection of sites, called hotspots (Iglesias and Carballo, 2010b), where energy is concentrated due to wave transformation phenomena, such as wave refraction.

In this framework, starting with a large set of offshore wave and wind data, the present paper discusses results related to estimating nearshore potential wave energy around the coast of Sicily.

This paper is organised as follows: the first part describes the adopted methodology selected to analyse wave propagation, and the second part focuses on the analysis of wave energy for the few selected sites along the coast of Sicily. The paper ends by summarising with some concluding remarks.

\section{Numerical simulation and validation}

\subsection{Numerical model}

The wave propagation is carried out using SWAN, which is a third-generation spectral model developed by Delft University of Technology (Booij et al., 1999). The model estimates the variations of the action density in space and time according to the following equation (expressed in Cartesian coordinates with the $x$ axis directed toward the coast):

$$
\frac{\partial N}{\partial t}+\frac{\partial c_{x} N}{\partial x}+\frac{\partial c_{y} N}{\partial y}+\frac{\partial c_{\sigma} N}{\partial \sigma}+\frac{\partial c_{\theta} N}{\partial \theta}=\frac{S_{\mathrm{ss}}}{\sigma}
$$

where $N$ is the action density that is equal to the energy density spectrum divided by the relative frequency. Equation (1) estimates the effect of $N$ in five dimensions (space $x$ and $y$, 

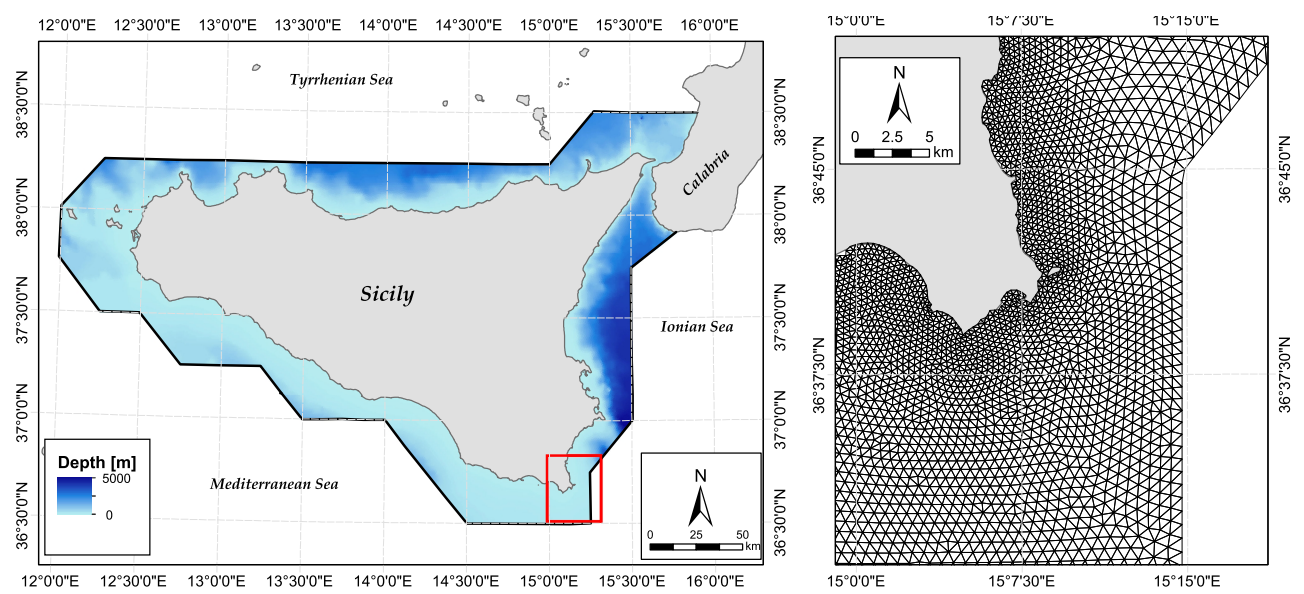

Figure 2. On the left: the bathymetry used to simulate wave propagation. On the right: detail of the model grid.

time $t$, frequency $\sigma$ and direction $\theta$ ). The quantities $c_{x}$ and $c_{y}$ are the components of the group velocities. The quantities $c_{\sigma}$ and $c_{\theta}$ are the propagation velocities in the spectral space $(\sigma, \theta)$. The first term of Eq. (1) indicates the change in time, the second and the third terms indicate the propagation of wave energy in two-dimensional space, the fourth term indicates the changes in the field of frequencies due to the variation of depth and currents and, finally, the fifth term indicates variations due to refraction induced by the variation of depth and currents. The right-hand side contains $S_{\mathrm{ss}}$, which is the source/sink term representing all physical processes that generate, dissipate, or redistribute wave energy.

$S_{\mathrm{ss}}=S_{\mathrm{in}}+S_{\mathrm{nl}}+S_{\mathrm{ds}}+S_{\mathrm{bot}}+S_{\mathrm{surf}}$,

where $S_{\text {in }}$ represents the momentum transfer of wind energy to wave generation, $S_{\mathrm{nl}}$ is the energy transfer due to nonlinear wave-wave interactions, $S_{\mathrm{ds}}$ is the dissipation of the energy due to white-capping (deep water wave breaking), $S_{\text {bot }}$ is the dissipation of the wave energy due to bottom friction, and $S_{\text {surf }}$ is the energy dissipation due to depth-induced wave breaking. In this study, $S_{\text {bot }}$ was not considered. Bottom friction was assumed negligible because the analyses are mainly focused for depths greater than or equal to $10 \mathrm{~m}$.

Stationary simulations were conducted using the bathymetric, wave and wind data as inputs. The wave data are defined in terms of significant wave height $H_{\mathrm{s}}$, peak period $T_{\mathrm{p}}$ and mean direction $\theta$. The wind data are defined in terms of the components of the wind.

\subsection{Input data}

The data used to reconstruct the morphology of the seabed were obtained from the charts of the Italian Navy Hydrographic Institute (NHI) and from the archive of General Bathymetric Chart of Oceans (GEBCO). The scale of the NHI charts is $1: 1000000$. GEBCO (released 2010) provides global bathymetry data sets for the world oceans with a resolution equal to $30 \mathrm{arcsec}$ (equivalent to $8.33^{\circ} \times 10^{-3}$ or approximately $1 \mathrm{~km})$ (GEBCO, 1999). The NHI charts cover a limited area of the computational domain and for this reason the data were integrated with the information of the GEBCO archive. More precisely, the seabed data up to a depth of $100 \mathrm{~m}$ were extracted from NHI, and the data for areas deeper than $100 \mathrm{~m}$ were extracted from the GEBCO archive. Figure 2 shows the final bathymetry used to simulate wave propagation.

Wind and wave input data were obtained from the ECMWF. The ECMWF is an independent intergovernmental organisation aimed at producing accurate climate data and medium-range forecasts, which are estimated using numerical models and validated according to data acquired via satellites, ships, buoys, etc. The estimate of offshore wave data is made up of the integration of the atmospheric model and the two-dimensional spectral wave numerical model, WAM. The resolution of the model in the Mediterranean Sea is equal to $0.25^{\circ}$ for both latitude and longitude. The ECMWF operational archive starts in 1989 for wind data and 1998 for wave data, with a time resolution equal to $6 \mathrm{~h}$.

Wave data were validated using records from the buoys of the Italian National Wave Recording Network (NWRN) managed by the Agency for Environmental Protection and Technical Services. The NWRN is composed by 15 buoys: eight of them were installed in 1989, while the remaining buoys were placed in the period 1999-2004. During the period 1989-2002, buoys acquired data for $30 \mathrm{~min}$ every $3 \mathrm{~h}$ and the measure becomes continuous for storms characterized by a significant wave height over a threshold. Since 2002, buoy measurements are continuous and the data are produced every half an hour. In the present study, available wave data to validate the ECMWF data are those of the three buoys placed near Catania, Capo Gallo (Palermo) and Mazara del Vallo (Trapani) (see Fig. 1 for the buoy locations). For such buoys the recording period periods are the following: (i) Catania July 1989-October 2006, with a to- 
Table 1. Performance indices of the ECMWF data: comparison between ECMWF data and buoy data.

\begin{tabular}{lllllllll}
\hline Wave characteristics & Buoy & sample & bias & RMSE & si & slope & $d$ & $R$ \\
\hline \multirow{3}{*}{ 0]*Significant wave height } & Catania & 8711 & $0.19 \mathrm{~m}$ & $0.33 \mathrm{~m}$ & 0.85 & 0.652 & 0.813 & 0.77 \\
& Capo Gallo & 4451 & $0.10 \mathrm{~m}$ & $0.32 \mathrm{~m}$ & 0.49 & 0.8 & 0.922 & 0.89 \\
& Mazara del Vallo & 9813 & $0.09 \mathrm{~m}$ & $0.28 \mathrm{~m}$ & 0.3 & 0.888 & 0.957 & 0.93 \\
\hline \multirow{3}{*}{ 0]*Wave period } & Catania & 7715 & $0.35 \mathrm{~s}$ & $1.73 \mathrm{~s}$ & 0.34 & 0.867 & 0.643 & 0.47 \\
& Capo Gallo & 4370 & $0.92 \mathrm{~s}$ & $1.87 \mathrm{~s}$ & 0.40 & 0.757 & 0.725 & 0.58 \\
& Mazara del Vallo & 9651 & $1.22 \mathrm{~s}$ & $1.67 \mathrm{~s}$ & 0.32 & 0.817 & 0.657 & 0.65 \\
\hline
\end{tabular}

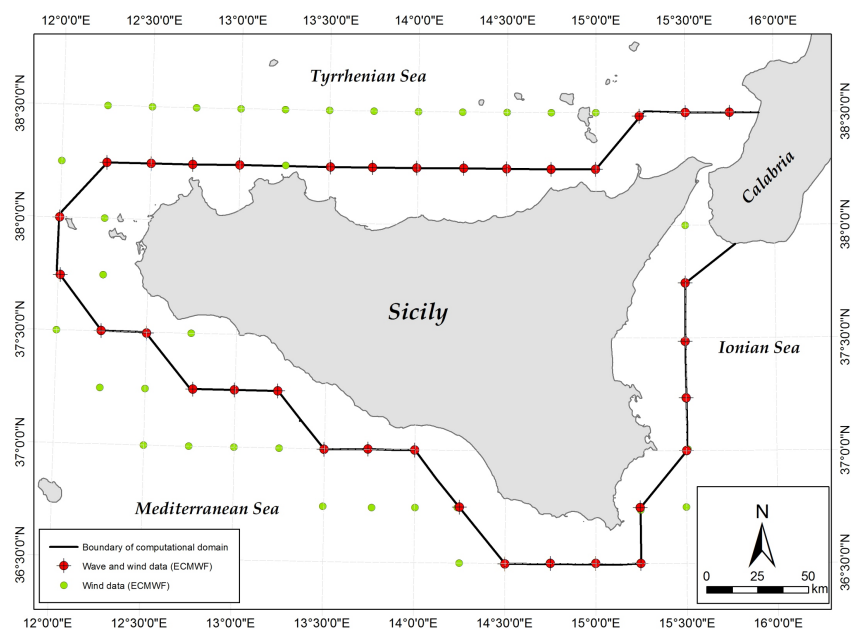

Figure 3. Localisation of the ECMWF grid points selected for the definition of the boundary conditions.

tal efficiency of $84 \%$; (ii) Capo Gallo January 2004-March 2008, with a total efficiency of $73 \%$; and (iii) Mazara del Vallo July 1989-April 2008, with a total efficiency of $79 \%$.

The reliability of the ECMWF data was measured by evaluating the following parameters: bias (bias, mean error between model and measurement), root mean square error (RMSE; root mean square discrepancy between the two sets of data), scatter index (si, normalised root mean square deviation in one of the sets of data), slope (slope, slope of the best fit line passing through the origin approximating the distribution of the two sets of data), Willmott index (Willmott, 1982) ( $d$ range limited to 0 and 1 , where 1 indicates a perfect matching), and coefficient of correlation $(R$, measure of the linear correlation between two sets of data). Such parameters are defined by the relationships shown in the Appendix.

The values assumed by the parameters in the present comparison are shown in Table 1. Regarding bias and RMSE, the differences between the two data sets are relatively small. It was observed that the higher value of the significant wave hight scatter index for the Catania buoys $(\mathrm{si}=0.85)$ is more likely due to a poor ability of the ECMWF numerical model to reproduce waves generated by local winds coming from the northeast. The values of the parameter slope are less than
1 and thus the ECMWF data tends to underestimate the actual sea status; however, this is limited to only certain events. Generally, such an underestimation occurs in closed basins, as in the present case. In such areas, the hindcast numerical models tend to underestimate the peak velocity of the wind and therefore lead to an underestimation of the significant wave height. The cause of this error is not fully understood, but as revealed by a study conducted as part of the WW-MEDATLAS (Cavaleri and Bertotti, 2004), it could be related to the modelling of the orography and of the marine boundary layer. The values of the parameter $d$ indicate generally good correspondence between the two data sets. The aim of this study was to estimate the average wave power. Therefore, the analysis performed using the ECMWF data to estimate onshore wave energy can be assumed to be conservative.

\subsection{Setting up the computational grid}

The computational domain here analysed was discretised using an unstructured grid. For the present case, the computational domain around Sicily was discretised with 4700 nodes and 89666 triangular elements. The grid resolution has been assumed constant for the depths shallower than $50 \mathrm{~m}$ and deeper than $100 \mathrm{~m}$, while it varies linearly in range $50-100 \mathrm{~m}$. Accordingly, the mesh sizes are $400 \mathrm{~m}$ for the depths shallower than 50, and $1000 \mathrm{~m}$ for the depths deeper than $100 \mathrm{~m}$, and varies linearly between 400 and $1000 \mathrm{~m}$ for the depths in the range of 50-100 $\mathrm{m}$ (see Fig. 2). The domain boundary was chosen to coincide with the polyline passing through 34 ECMWF grid points around Sicily. The 34 grid points were selected at depths on the order of $100 \mathrm{~m}$ (see Fig. 3). The wave data of such points were used to define the boundary conditions of the computational domain. Furthermore, to estimate wave regeneration during propagation, 32 additional ECMWF grid points were selected to define the wind field over the entire computational domain (see Fig. 3). At each node of the SWAN domain, the wind data were defined by interpolation using the inverse distance interpolation weighted method. The wave input at each boundary segment was defined using the JONSWAP (Joint North Sea Wave Project) spectrum. The spectrum was discretised into 36 directions 
Table 2. Performance indices of the SWAN model: comparison between the SWAN data and satellite data.

\begin{tabular}{|c|c|c|c|c|c|c|c|c|}
\hline Satellite & Reference period & samples & bias $[\mathrm{m}]$ & RMSE [m] & si $[-]$ & slope $[-]$ & $d[-]$ & $R[-]$ \\
\hline ERS-2 & 15 May 1995 to $04 \mathrm{Jul} 2011$ & 2255 & 0.10 & 0.48 & 0.503 & 0.860 & 0.887 & 0.80 \\
\hline Envisat & 14 May 2002 to 08 Apr 2012 & 141 & 0.21 & 0.39 & 0.368 & 0.8550 & 0.9213 & 0.89 \\
\hline Topex-Poseidon & 25 Sep 1992 to 08 Oct 2005 & 3345 & 0.20 & 0.39 & 0.480 & 0.814 & 0.913 & 0.88 \\
\hline Jason-1 & 15 Jan 2002 to 15 Feb 2013 & 1017 & 0.28 & 0.45 & 0.48 & 0.77 & 0.90 & 0.89 \\
\hline GeoSat Follow-On & 07 Jan 2000 to 07 Sep 2008 & 731 & 0.28 & 0.43 & 0.454 & 0.766 & 0.857 & 0.84 \\
\hline Jason-2 & $04 \mathrm{Jul} 2008$ to $01 \mathrm{Feb} 2013$ & 155 & 0.21 & 0.40 & 0.457 & 0.800 & 0.900 & 0.87 \\
\hline CryoSat-2 & 28 Jan 2011 to 08 Apr 2013 & 701 & 0.17 & 0.38 & 0.474 & 0.861 & 0.914 & 0.87 \\
\hline
\end{tabular}
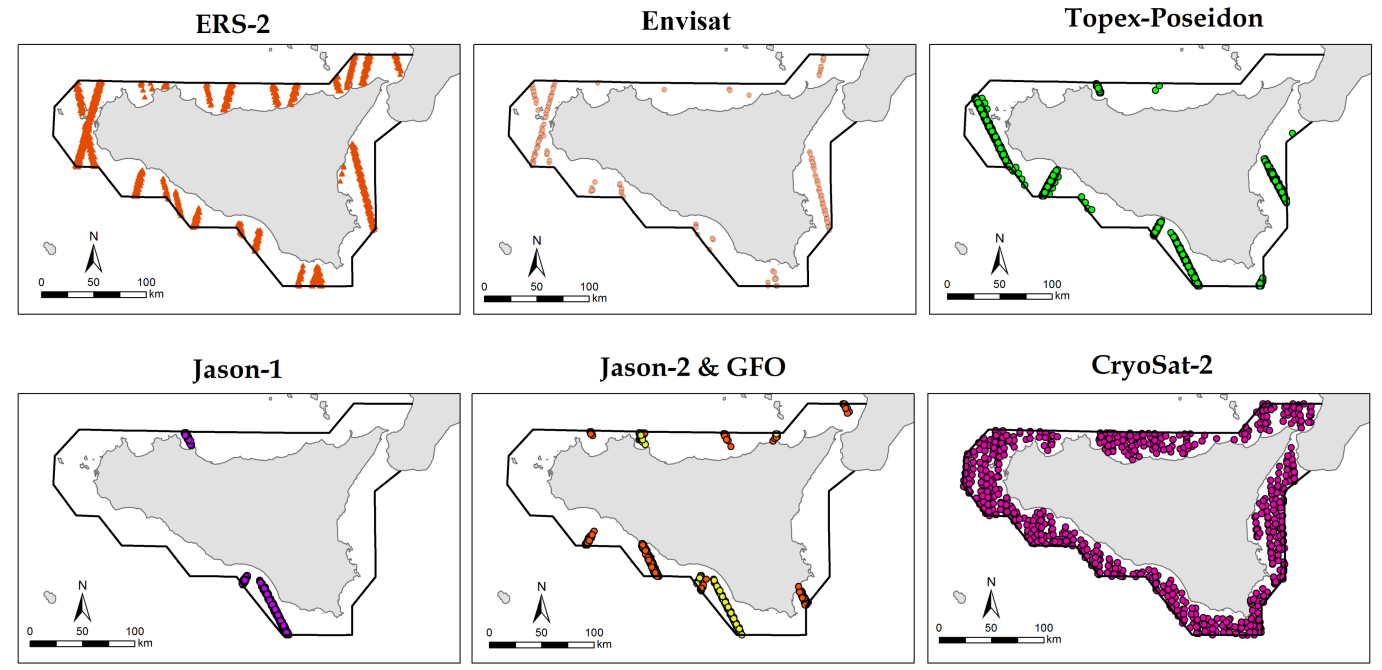

Figure 4. Observation points from satellites, selected within the computational domain for validating SWAN model results.

and 40 frequencies in a range of $0.04-0.5 \mathrm{~Hz}$, which corresponds to range of $2-25 \mathrm{~s}$ in terms of time.

\subsection{Validation of the output data}

Validation of the significant wave height estimated using the models was conducted by performing a comparison with data collected from several satellites and processed by the French Research Institute for Exploitation of the Sea (IFREMER). The IFREMER database provided wave heights at the global scale over the period of 1991-2013. In particular, the wave heights are derived from measurements made by seven satellites (ERS2, Envisat, Topex-Poseidon, Jason-1 and 2, GeoSat FO, CryoSat-2) calibrated according to the method developed by Queffeulou (2004). For additional details, interested readers are referred to Queffeulou and Croizé-Fillo (2013). Satellite data from the Envisat, ERS-2, and Jason-1 and 2 were used for the operational assimilation of wave height data in the ECMWF model. Satellite data from ERS-2 were used over the period 1995-2003, from Envisat since 2003, from Jason-1 since 2006 and from Jason-2 since 2009. These assimilation periods will be excluded for the validation of SWAN data. The selected observation points are shown in
Fig. 4. The validation of the data from the SWAN model with the satellite data was performed using the parameters defined in the Appendix, and the results are shown in Table 2. The comparison shows a fairly good agreement. In fact, the values of RMSE are under $0.5 \mathrm{~m}$, and a maximum value of $0.50 \mathrm{~m}$ was reached for the data acquired from the ERS-2 satellite. The values of slope are all less than 1, indicating that the model data tended to underestimate the values of the significant wave heights. These results are due to the boundary conditions gathered for the ECMWF data, which tend to underestimate the peak events, as described above. Figure 5 shows a scatter plot of the output of the SWAN model and the significant wave heights estimated by the Jason-1 satellite.

\section{Wave energy resource}

\subsection{Method}

The components of wave energy transport $P$ are defined as 


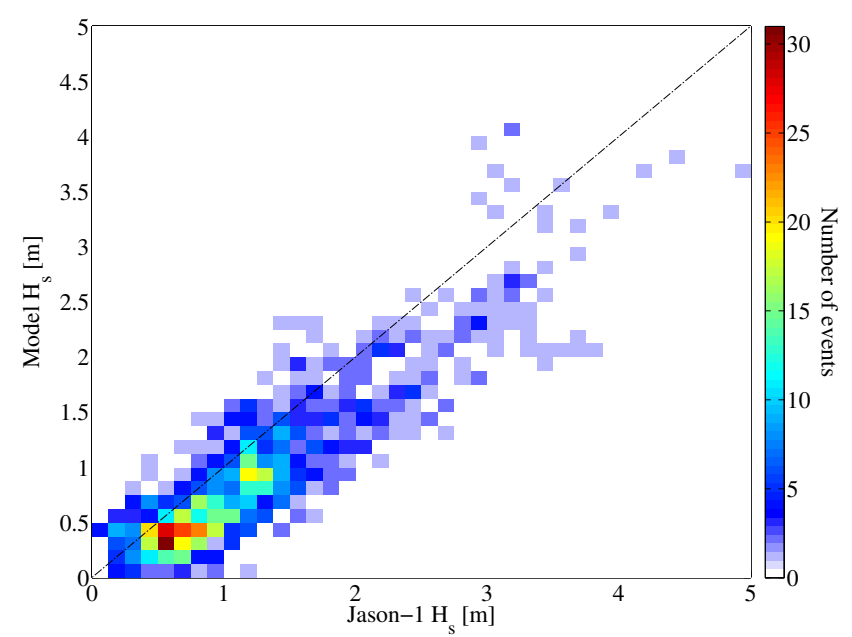

Figure 5. Comparison of the significant wave height evaluated by the SWAN model and by Jason 1 satellite data.

$$
\begin{aligned}
P_{x} & =\int_{0}^{2 \pi} \int_{0}^{\infty} c_{x} E(\sigma, \theta) \mathrm{d} \sigma \mathrm{d} \theta, \\
P_{y} & =\int_{0}^{2 \pi} \int_{0}^{\infty} c_{y} E(\sigma, \theta) \mathrm{d} \sigma \mathrm{d} \theta,
\end{aligned}
$$

where $E$ is the energy spectral density. For deep waters, the total wave energy transport can be rewritten as

$P=\frac{\rho g^{2} H_{m 0}^{2} T_{\mathrm{e}}}{64 \pi}$,

where $\rho$ is the density of water, $g$ is the acceleration due to gravity, $H_{m 0}$ is the significant wave height, and $T_{\mathrm{e}}$ is the energy period. The significant wave height $H_{m 0}$ and the energy period $T_{\mathrm{e}}$ are defined by the following relationships:

$$
\begin{aligned}
& H_{m 0}=4\left(m_{0}\right)^{0.5}=4\left(\int_{0}^{2 \pi} \int_{0}^{\infty} S(\sigma, \theta) \mathrm{d} \sigma \mathrm{d} \theta\right)^{0.5}, \\
& T_{\mathrm{e}}=\frac{m_{-1,0}}{m_{0}}=2 \pi\left(\frac{\int_{0}^{2 \pi} \int_{0}^{\infty} \sigma^{-1} S(\sigma, \theta) \mathrm{d} \sigma \mathrm{d} \theta}{\int_{0}^{2 \pi} \int_{0}^{\infty} S(\sigma, \theta) \mathrm{d} \sigma \mathrm{d} \theta}\right),
\end{aligned}
$$

where $S$ is the variance density spectrum and $m_{n}$ represents the spectral moment of order $N$.

It was noted that, in some cases, to estimate the wave energy resources, Eq. (4) is used indiscriminately for both $\frac{h}{L}>1 / 2$ (deep waters) and $\frac{h}{L}<1 / 2$ (intermediate and shallow waters). However, Barbariol et al. (2013) reported that the use of Eq. (4) underestimates the value of the wave energy if it is applied for the case of $\frac{h}{L}<1 / 2$. Extending the analysis conducted in Barbariol et al. (2013), we compared the two methods assuming a TMA (Texel-Marsen-Arsloe) spectrum. According to a previously reported formulation (Tucker, 1994), the TMA spectrum can be expressed as follows:

$S_{\mathrm{TMA}}(\sigma)=S_{\mathrm{J}}(\sigma) \cdot \phi(k h)$,

where $S_{\mathrm{J}}(\sigma)$ is the JONSWAP spectrum, $k$ is the wave number, $h$ is the water depth and the function $\phi(k h)$ is defined as

$\phi(k h)=\frac{\tan ^{2} k h}{1+\frac{2 k h}{\sinh (2 k h)}}$.

Figure 6 shows the relative difference $\Delta_{P}$ between the wave energy transport estimated using Eq. (3) and calculated using Eq. (4). The relative difference $\Delta_{P}$ is defined by the following relationship:

$\Delta_{P}=\frac{P_{\mathrm{dw}}-P_{\mathrm{sw}}}{P_{\mathrm{sw}}}$,

where $P_{\mathrm{dw}}$ and $P_{\mathrm{sw}}$ are the wave energy transports estimated according to Eqs. (4) and (3), respectively. In particular, in Fig. 6a, the relative difference is plotted as a function of the peak period and the depth (the lines indicate the ratio between the depth and the wavelength). In Fig. $6 \mathrm{~b}$ the relative difference is plotted as a function of the peak period and the ratio $\frac{h}{L}$. For $\frac{h}{L}$ greater than 0.4 , there are no differences between the two methods. The difference approaches $-15 \%$ when the $\frac{h}{L}$ is within the range of $0.12-0.26$, whereas the difference increases for values of $\frac{h}{L}$ lower than 0.12 . For $\frac{h}{L}$ less than 0.07, Eq. (4) overestimates the value of the wave energy transport. The graph cannot be generalised because it changes with the input spectrum, although if the sea state corresponds to a value of $\frac{h}{L}$ greater than 0.4 and in the range approximately between 0.07 and 0.10 , either method may be used. Conversely, if $\frac{h}{L}$ falls outside of the previous range, the maximum relative error is approximately $-15 \%$, and it is recommended to use Eq. (3). Moreover, as shown in Fig. 6b, the difference is minimally influenced by the peak period only for a peak period near $2 \mathrm{~s}$.

For the present study, Fig. 7 shows the comparison between the energy transport estimated according to Eqs. (3) and (4). The comparison was affected along the red line indicated in Fig. 7 for a sea state with an offshore significant wave height of $2 \mathrm{~m}$ and a peak period of $10 \mathrm{~s}$. Note that the maximum difference between the two formulas is approximately $10 \%$. Such a difference is relatively low and of the same order of uncertainty that is present in the input wave data.

\subsection{Analysis of results}

For each sea state propagated up to the coast (one every $6 \mathrm{~h}$ from 01 January 1999 to 31 December 2012), the associated 


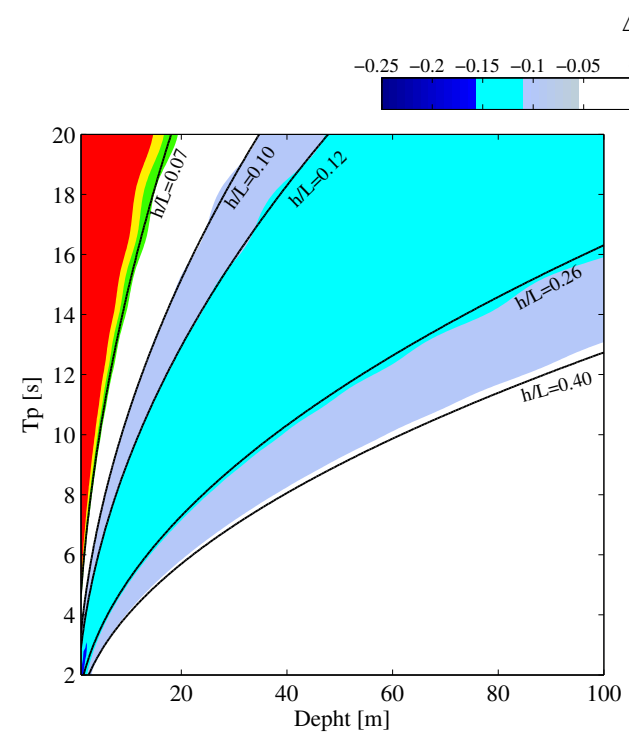

(a)

$\Delta_{\mathrm{p}}$

$\begin{array}{lllll}0.05 & 0.1 & 0.15 & 0.2 & 0.25\end{array}$

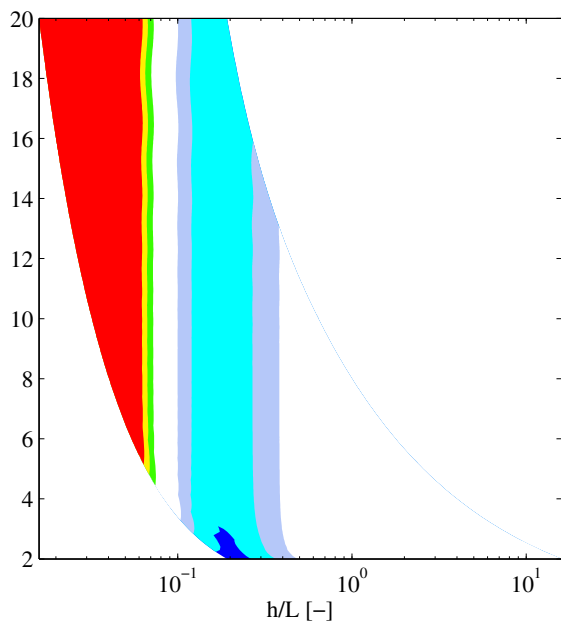

(b)

Figure 6. Comparison between Eqs. (3) and (4): (a) the relative difference $\Delta_{P}$ is plotted as function of the peak period and the depth (the lines indicate the ratio between the depth and the wavelength.); (b) the relative difference $\Delta_{P}$ is plotted as function of the peak period and the ratio $\frac{h}{L}$.

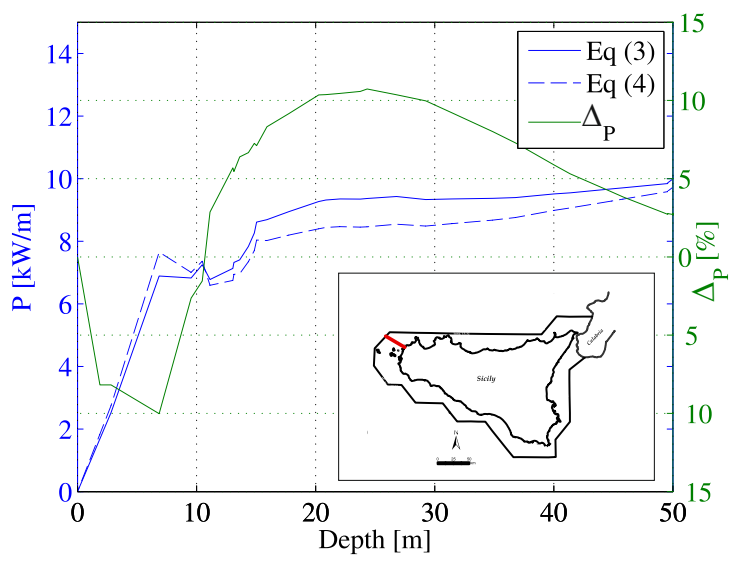

Figure 7. Comparison between Eqs. (3) and (4) along the red line indicated in the map for a case study: offshore significant wave height in the nearest boundaries of approximately of $2 \mathrm{~m}$ with a mean period of $10 \mathrm{~s}$.

energy flux was obtained (see Fig. 8). On the boundary of the domain the wave energy flux is consistent with the results of Liberti et al. (2013). In detail, an energy flux close to $8 \mathrm{~kW} \mathrm{~m}^{-1}$ is observed on the western side, whereas in the Strait of Sicily, a flux in the range $4-6 \mathrm{~kW} \mathrm{~m}^{-1}$ is detected. The wave energy flux is further reduced to $2-3 \mathrm{~kW} \mathrm{~m}^{-1}$ on the north and east sides of Sicily, respectively. As shown in Iuppa et al. (2014), where preliminary results of the present study are reported, the areas with highest wave energy have a low variation in wave power over the period studied. For

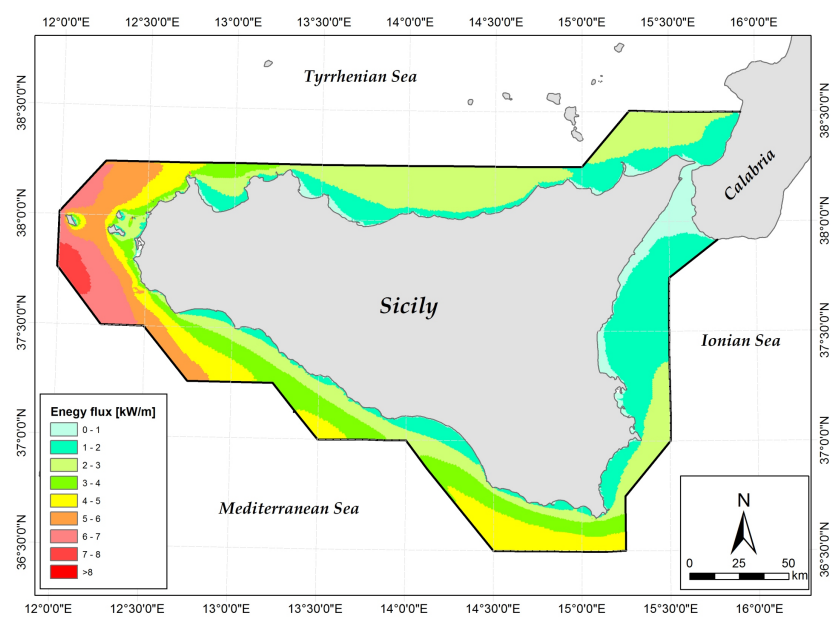

Figure 8. Distribution of the average wave energy flux per unit crest length within the computational domain.

these zones, the ratio between the standard deviation and the average of the yearly mean wave power flux is below 0.35 .

Figure 9 shows the seasonal distribution of the wave energy flux. The data are regrouped according to the following months: (a) December, January and February (DJF); (b) March, April and May (MAM); (c) June, July and August (JJA); and (d) September, October and November (SON). As expected, the energy flux in the DJF period is higher than in the other periods. The JJA period shows a significant reduction compared to the DJF period, which ranges approximately from 60 to $80 \%$. 

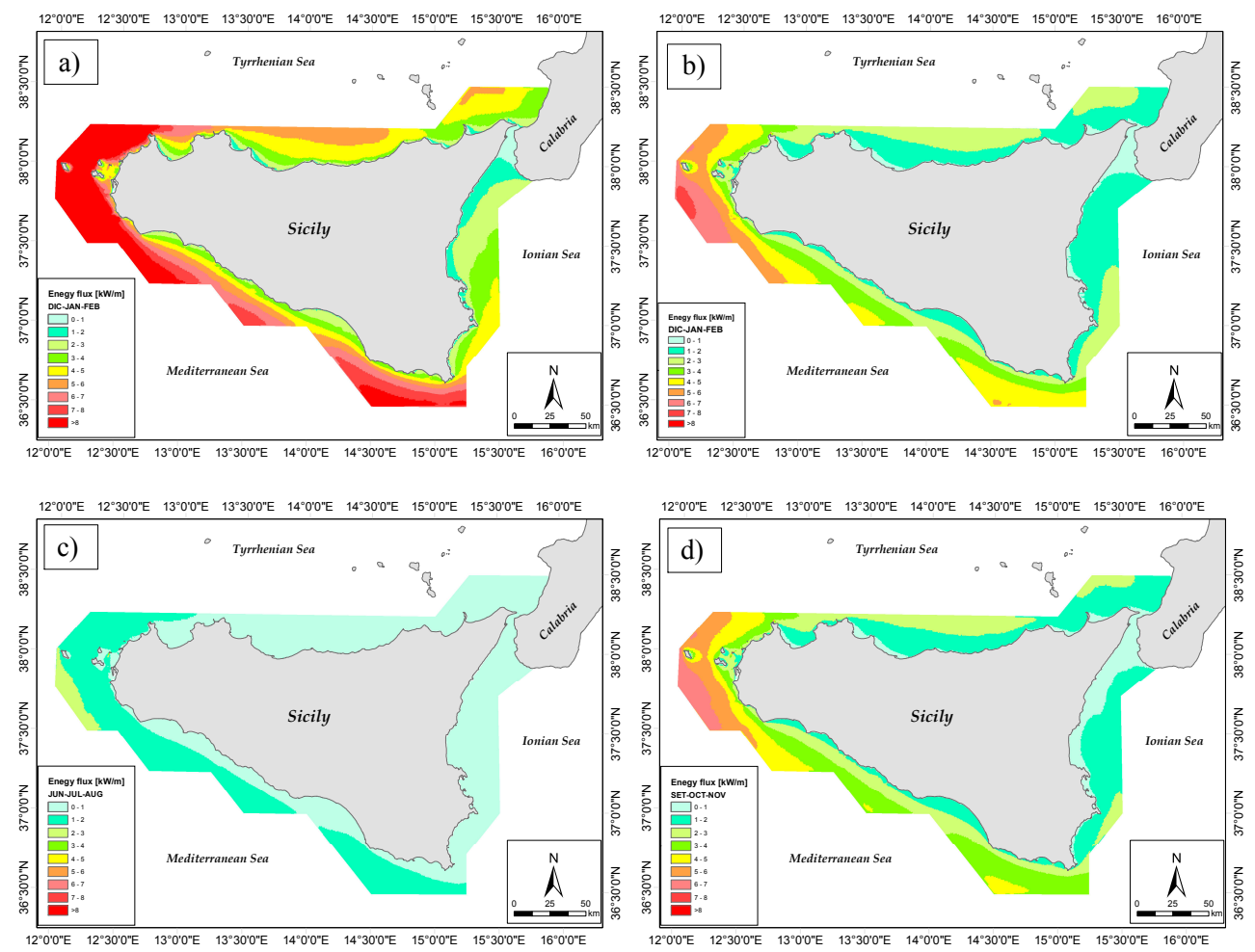

Figure 9. Seasonal distribution of the average wave energy flux per unit crest length within the computational domain. (a) December, January and February; (b) March, April and May; (c) June, July and August; (d) September, October and November.

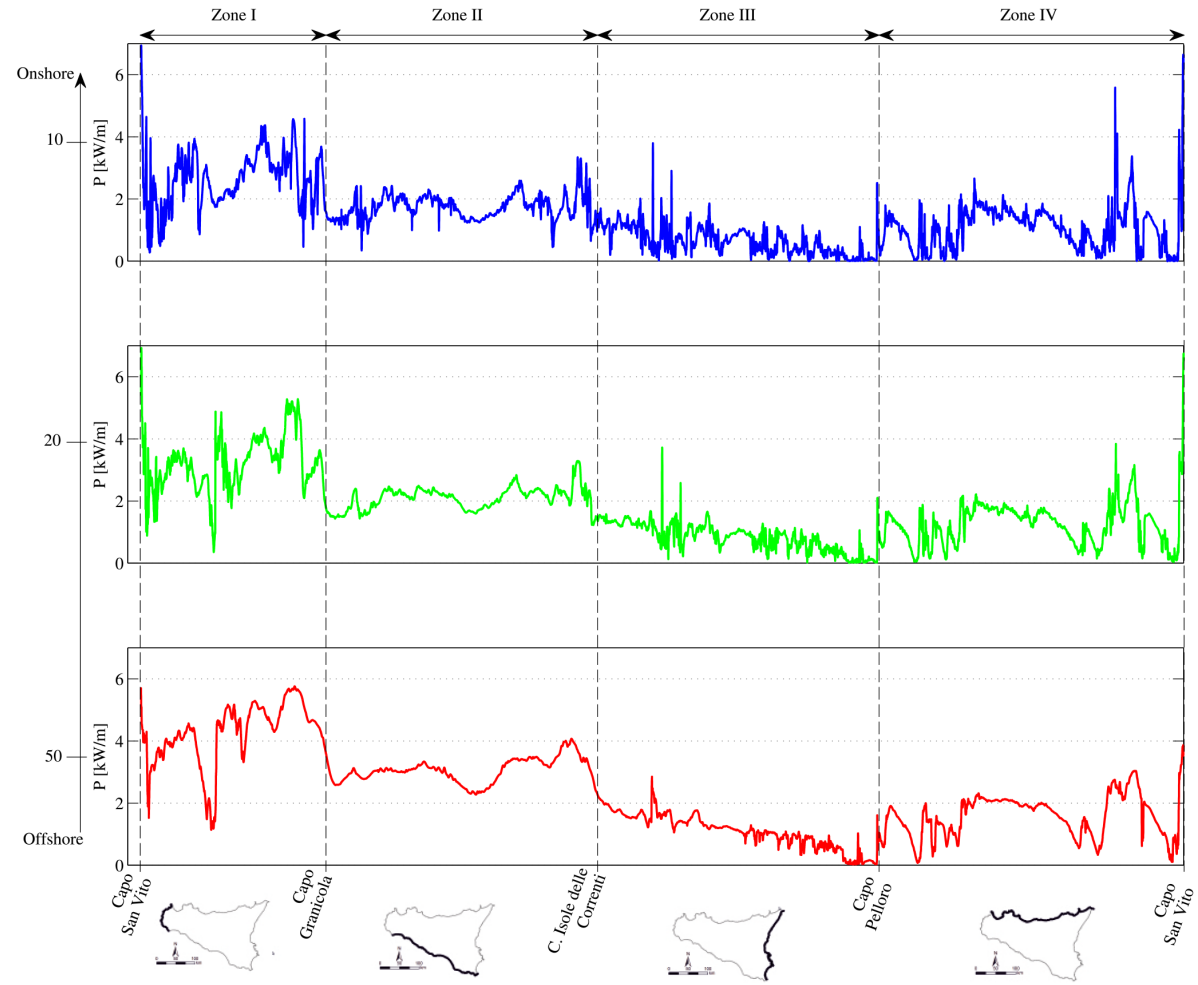

Figure 10. Distribution of the wave energy flux around Sicily estimated along three different isobaths: (a) $-10 \mathrm{~m} ;(\mathbf{b})-20 \mathrm{~m} ;(\mathbf{c})-50 \mathrm{~m}$. 
Table 3. Sites selected in proximity of the Sicilian coast. For each site the table shows the geographical coordinates, the depth, the annual average wave power, the annual average wave energy, the distance between the sites and the coast $D_{\mathrm{c}}$, the distance between the sites and the nearest port $D_{\mathrm{p}}$, and the name of the port.

\begin{tabular}{lllllllll}
\hline Site & $\begin{array}{l}\text { Coordinates } \\
\text { long }\left[^{\circ}\right]\end{array}$ & lat $\left[^{\circ}\right]$ & $\begin{array}{l}\text { Depth } \\
{[\mathrm{m}]}\end{array}$ & $\begin{array}{l}\text { Power } \\
{\left[\mathrm{kW} \mathrm{m}^{-1}\right]}\end{array}$ & $\begin{array}{l}\text { Energy } \\
{\left[\mathrm{MWh} \mathrm{m}^{-1}\right]}\end{array}$ & $\begin{array}{l}D_{\mathrm{c}} \\
{[\mathrm{km}]}\end{array}$ & $\begin{array}{l}D_{\mathrm{p}} \\
{[\mathrm{km}]}\end{array}$ & Port \\
\hline HS1 & 13.08 & 38.19 & 13.80 & 3.34 & 29.26 & 1.00 & 3.00 & Terrasini \\
HS2 & 12.77 & 38.18 & 10.00 & 5.49 & 48.09 & 0.50 & 3.00 & San Vito Lo Capo \\
HS3 & 12.74 & 38.20 & 16.30 & 7.52 & 65.88 & 1.50 & 2.00 & San Vito Lo Capo \\
HS4 & 12.53 & 38.04 & 10.00 & 4.22 & 36.97 & 0.50 & 3.50 & Trapani \\
HS5 & 12.27 & 37.94 & 10.00 & 6.88 & 60.27 & 0.50 & 7.00 & Favignana \\
HS6 & 12.04 & 37.96 & 10.00 & 6.38 & 55.89 & 0.50 & 9.00 & Marettimo \\
HS7 & 12.41 & 37.80 & 10.00 & 4.36 & 38.19 & 1.00 & 1.20 & Marsala \\
HS8 & 12.47 & 37.65 & 21.00 & 5.40 & 47.30 & 4.00 & 9.00 & Mazara del Vallo \\
\hline
\end{tabular}

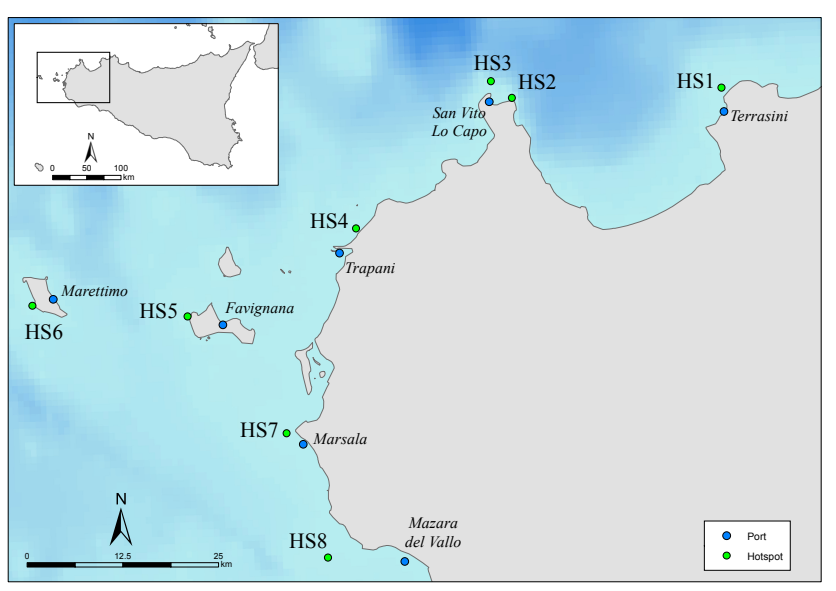

Figure 11. Locations of the selected hotspots and relative nearest ports where WECs could be located.

Figure 10 shows the comparison of the average power estimate corresponding to the bathymetric lines at depths of 10,20 and $50 \mathrm{~m}$. According to a coarse analysis at a regional scale, we identified four zones with nearly homogeneous values: the first between Capo San Vito and Capo Granitola (zone I), the second between Capo Granitola and Capo Isola delle Correnti (zone II), the third between the Capo Isola delle Correnti and Capo Peloro (zone III), and finally, the fourth between Capo Peloro and Capo San Vito (zone IV). In the first zone, the energy flux does not exhibit a substantial variance from depths of 50-10 $\mathrm{m}$ and the reduction is approximately $1-2 \mathrm{~kW} \mathrm{~m}^{-1}$. However, the presence of small islands provides coastal protection by reducing the nearshore wave energy. This part of the coast is characterised by waves that primarily come from the sector of $260-290^{\circ} \mathrm{N}$. Such waves are almost perpendicular to the coastline; therefore, when they travel from offshore to the shoreline, they suffer from little energy dispersion (due to refraction). In the second zone the energy spatial dispersions (due to refraction) are more sensitive and the values of the wave energy flux are lower.
However, from the depths of 50-10 $\mathrm{m}$ the energy reductions are smaller, approximately less than $1 \mathrm{~kW} \mathrm{~m}^{-1}$. In the third zone, the energy flux is lower because the wave heights are less than $0.5 \mathrm{~m}$ for most of the time (see the wave climate of the buoy of Catania in Fig. 1). However, this zone contains point energy values near to $3.5 \mathrm{~kW} \mathrm{~m}^{-1}$. In the fourth zone, there are areas of high energy alternating with areas of low energy. Even in this case, there exist some points where the energy grows drastically.

\section{Hotspot selections}

In this study we selected six sites characterised by high energy content between zone I and zone IV and an additional two sites near the islands of Favignana and Marettimo. Figure 11 shows the locations of the hotspots selected, and $\mathrm{Ta}-$ ble 3 presents their principal characteristics.

The sites were analysed to understand how the energy is distributed with respect to the significant wave height, the energy period, the direction and the seasons. Figures 12-15 show the wave energy distribution with respect to the energy period and the significant wave height for the selected sites. Figure 16 shows the wave climate. Table 4 shows both the probability of occurrence for the classes $T_{\mathrm{e}}-H_{m 0}$ and the direction at which the wave energy is concentrated and the probability of "no-calm" occurrences; thus, waves with a significant wave height greater than $0.5 \mathrm{~m}$ are shown. Finally, Table 5 summarises the seasonal distribution of the average wave energy flux.

The SH1 site is located in zone IV near the port of Terrasini. Here, the power density is relatively lower than that of the other sites, although it is nearly equal to that observed offshore. The wave energy is concentrated in the classes over a range of 6-8.5 s with respect to the $T_{\mathrm{e}}$ and between 1 and $3.5 \mathrm{~m}$ with respect to $H_{m 0}$, with an annual frequency of $12.55 \%$ (approximately 46 days year ${ }^{-1}$ ). The percent of "no calm" is approximately $47.72 \%$. Waves with high energy content come from the sector at $290-320^{\circ} \mathrm{N}$ with a frequency of $49.81 \%$. The wave energy flux is slightly greater 
Table 4. Occurrence frequency of the most energetic $T_{\mathrm{e}}-H_{m 0}$ and direction intervals. For each site the frequency of "non-calm" conditions are also reported.

\begin{tabular}{lllllll}
\hline Sites & $H_{m 0}[\mathrm{~m}]$ & $T_{\mathrm{e}}[\mathrm{s}]$ & frequency [\%] & $\operatorname{Dir}\left[{ }^{\circ} \mathrm{N}\right]$ & frequency [\%] & $\begin{array}{l}\text { non-calm } \\
\text { frequency [\%] }\end{array}$ \\
\hline HS1 & $1.0-3.5$ & $6-8.5$ & 12.55 & $290-320$ & 49.81 & 47.72 \\
HS2 & $2.0-4.0$ & $6.0-10$ & 10.74 & $350-10$ & 47.83 & 56.98 \\
HS3 & $2.0-4.5$ & $6.0-8.5$ & 7.05 & $310-330$ & 43.11 & 61.07 \\
HS4 & $2.0-3.5$ & $6.5-9.0$ & 6.00 & $310-320$ & 32.93 & 49.53 \\
HS5 & $1.5-3.5$ & $6.0-10$ & 25.97 & $280-290$ & 31.93 & 69.88 \\
HS6 & $1.5-4.5$ & $5.5-10$ & 19.89 & $270-300$ & 40.80 & 67.42 \\
HS7 & $1.5-3.5$ & $6.0-10$ & 11.65 & $270-280$ & 31.30 & 61.12 \\
HS8 & $1.0-4.0$ & $5.0-9.0$ & 27.84 & $270-300$ & 40.35 & 66.77 \\
\hline
\end{tabular}

Table 5. Seasonal distribution of the average wave energy flux per unit crest length for the selected sites.

\begin{tabular}{|c|c|c|c|c|c|c|c|c|}
\hline & \multicolumn{2}{|c|}{ DJF } & \multicolumn{2}{|c|}{ MAM } & \multicolumn{2}{|c|}{ GLA } & \multicolumn{2}{|c|}{ SON } \\
\hline & $\begin{array}{l}\mathrm{P} \\
{\left[\mathrm{kW} \mathrm{m}^{-1}\right]}\end{array}$ & $\begin{array}{l}\mathrm{E} \\
{[\mathrm{MWh}]}\end{array}$ & $\begin{array}{l}\mathrm{P} \\
{\left[\mathrm{kW} \mathrm{m}^{-1}\right]}\end{array}$ & $\begin{array}{l}\mathrm{E} \\
{[\mathrm{MWh}]}\end{array}$ & $\begin{array}{l}\mathrm{P} \\
{\left[\mathrm{kW} \mathrm{m}^{-1}\right]}\end{array}$ & $\begin{array}{l}\mathrm{E} \\
{[\mathrm{MWh}]}\end{array}$ & $\begin{array}{l}\mathrm{P} \\
{\left[\mathrm{kW} \mathrm{m}^{-1}\right]}\end{array}$ & $\begin{array}{l}\mathrm{E} \\
{[\mathrm{MWh}]}\end{array}$ \\
\hline HS1 & 6.72 & 58.84 & 2.76 & 24.22 & 0.96 & 8.41 & 2.78 & 24.37 \\
\hline HS2 & 10.06 & 88.11 & 4.91 & 42.97 & 1.96 & 17.19 & 4.82 & 42.27 \\
\hline HS3 & 15.05 & 131.86 & 6.37 & 55.81 & 1.86 & 16.25 & 6.38 & 55.91 \\
\hline HS4 & 8.11 & 71.03 & 3.67 & 32.12 & 1.36 & 11.94 & 3.61 & 31.58 \\
\hline HS5 & 11.44 & 100.25 & 6.62 & 58.02 & 2.75 & 24.11 & 6.31 & 55.31 \\
\hline HS6 & 10.93 & 95.72 & 6.12 & 53.58 & 1.87 & 16.34 & 6.10 & 53.44 \\
\hline HS7 & 7.93 & 69.46 & 4.07 & 35.66 & 1.29 & 11.28 & 3.93 & 34.46 \\
\hline HS8 & 9.82 & 85.99 & 5.14 & 45.00 & 1.51 & 13.26 & 4.84 & 42.38 \\
\hline
\end{tabular}

than $5 \mathrm{~kW} \mathrm{~m}^{-1}$ for the winter months, whereas for the summer months the value is reduced to almost $1 \mathrm{~kW} \mathrm{~m}^{-1}$.

The sites HS2 and HS3 are both located near the port of San Vito Lo Capo. However, they exhibit different energy distributions with to respect both $H_{m 0}-T_{\mathrm{e}}$ and the direction.

At HS2, the waves tend to be aligned to the coast and the energy is focused in a more restricted range of $H_{m 0}-T_{\mathrm{e}}$. The wave energy is concentrated in the range of 6-8.5 s and 1$3.5 \mathrm{~m}$, with an annual frequency of $10.74 \%$ (approximately 39 days year ${ }^{-1}$ ). The percent of "no calm" is approximately $56.98 \%$ with waves coming predominantly from the sector between 350 and $10^{\circ} \mathrm{N}$ and characterised by a frequency of $47.83 \%$. The wave energy flux is slightly greater than $10 \mathrm{~kW} \mathrm{~m}^{-1}$ for the winter months, whereas for the summer months, the value is reduced to $2 \mathrm{~kW} \mathrm{~m}^{-1}$.

At HS3, the waves with more energy and frequency are concentrated in the range of 6-8.5 s with respect to $T_{\mathrm{e}}$ and between 2 and $4.5 \mathrm{~m}$ with respect to $H_{m 0}$, with a frequency of $7.05 \%$ (approximately 26 days year $^{-1}$ ). Here, the waves come predominantly from the sector between 310 and $330^{\circ} \mathrm{N}$ with a frequency of $43.11 \%$.

Site HS4 is located near the port of Trapani. The wave energy is concentrated in the range of $6.5-9 \mathrm{~s}$ with respect to $T_{\mathrm{e}}$ and between $2-3.5 \mathrm{~m}$ with respect to $H_{m 0}$, with an annual frequency of $6.0 \%$ (approximately 22 days year ${ }^{-1}$ ). The per- cent of "no calm" is approximately $49.53 \%$. More energetic waves come from the sector at $310-320^{\circ} \mathrm{N}$, with a frequency of $32.93 \%$. The seasonal variation is fairly high (approximately $88 \%$ ).

The site SH5 is located near the west coast of Favignana Island. It has a good exposure regarding energetic waves. The wave energy flux is approximately $6.88 \mathrm{~kW} \mathrm{~m}^{-1}$. More energetic waves have a frequency of $25.97 \%$ (approximately 95 days year $^{-1}$ ). As observed for the $\mathrm{SH} 2$ site, the energy is more concentrated in a fewer number of bins than occurs at the other sites. The dominant directions are in the sector 280$290^{\circ} \mathrm{N}$ with a frequency of $31.93 \%$. However, the maximum seasonal variation between the winter and summer months is approximately $75 \%$.

The SH6 site is located near the west coast of the Marettimo Island. The sites exhibits a different exposure from that at the SH5 site. The wave energy is concentrated in the range of $5.5-10 \mathrm{~s}$ with respect to $T_{\mathrm{e}}$ and $1.5-4.5 \mathrm{~m}$ with respect to $H_{m 0}$, with an annual frequency of $19.89 \%$ (approximately 73 days year ${ }^{-1}$ ). The percent of "no calm" is approximately $67.42 \%$. The dominant directions are in the sector at $270-280^{\circ} \mathrm{N}$ with a frequency of $40.80 \%$. Wave energy flux is slightly greater than $10 \mathrm{~kW} \mathrm{~m}^{-1}$ for the winter months, whereas for the summer months a reduction to $1.87 \mathrm{~kW} \mathrm{~m}^{-1}$ is observed. 


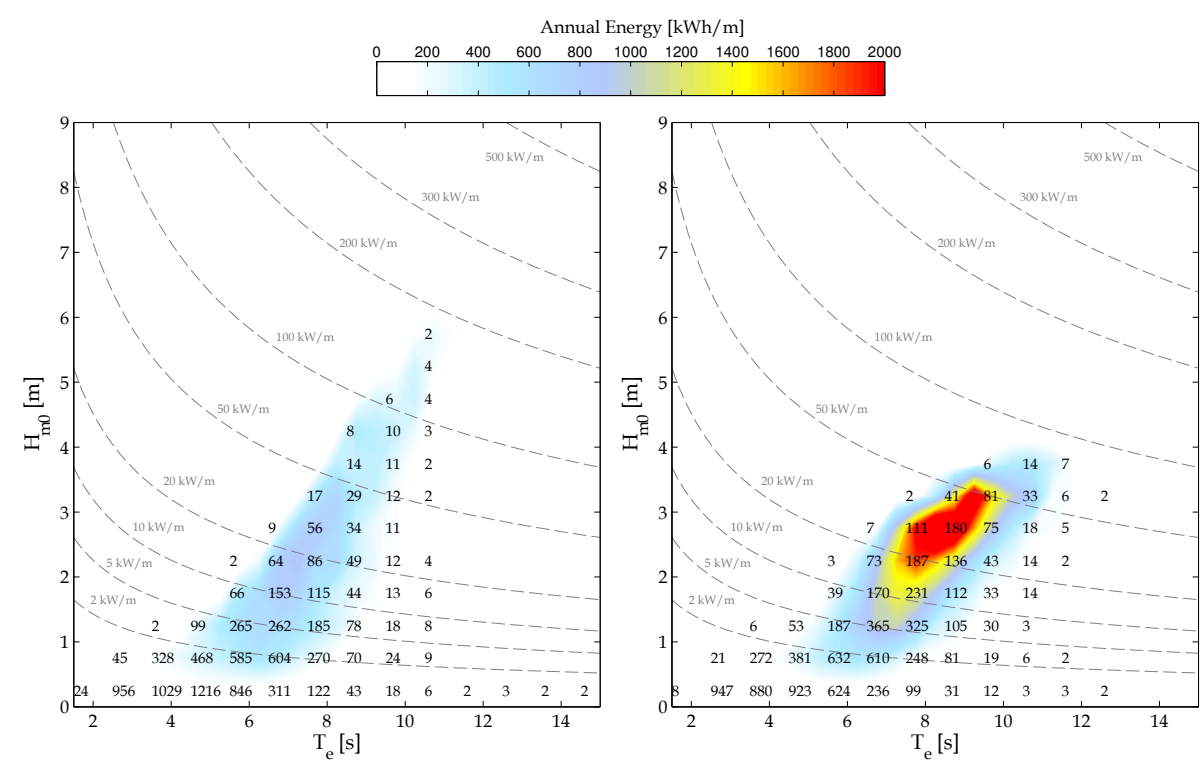

Figure 12. Characterisation of the yearly average wave energy in terms of significant wave height $H_{m 0}$ and energy period $T_{\mathrm{e}}$ : on the left site HS1 and on the right site HS2. The colour scale represents annual energy per metre of wave front (in MWh $\mathrm{m}^{-1}$ ). The numbers within the graph indicate the occurrence of sea states (in number of hours per year).
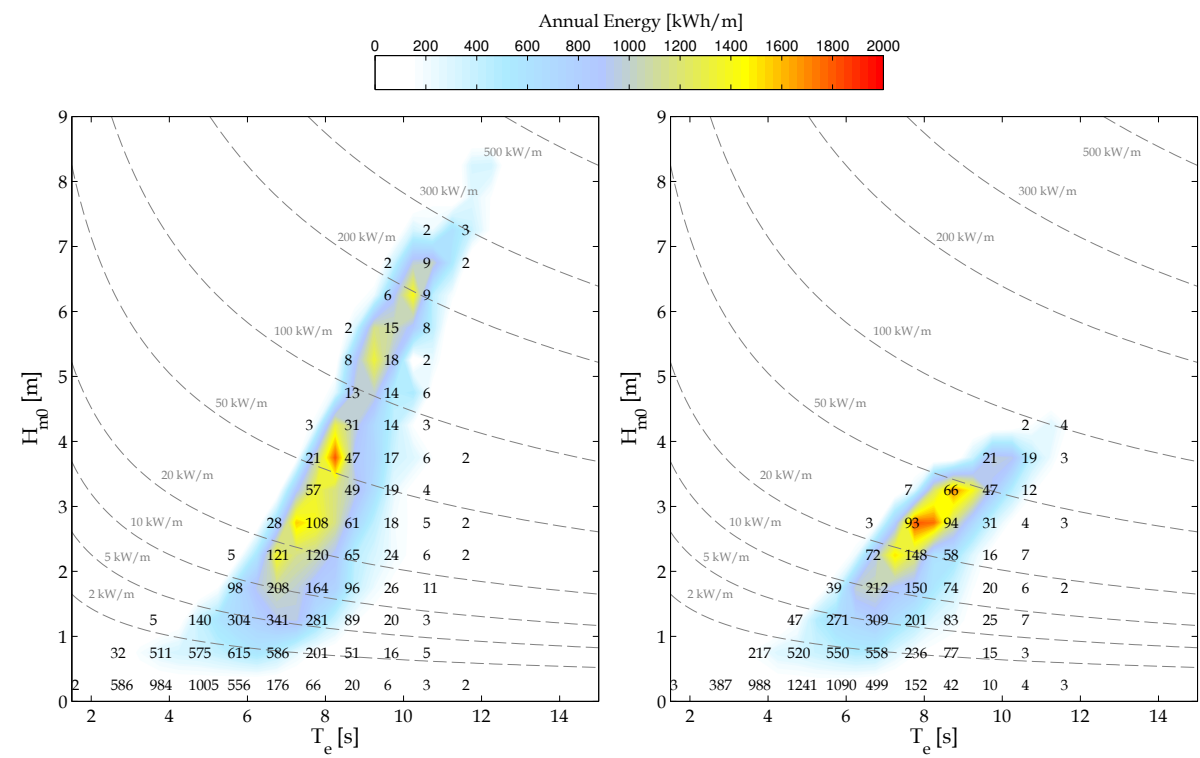

Figure 13. Characterisation of the yearly average wave energy in terms of $H_{m 0}$ and $T_{\mathrm{e}}$ : on the left site HS3 and on the right site HS4. The colour scale represents annual energy per metre of wave front (in $\mathrm{MWh} \mathrm{m}^{-1}$ ). The numbers within the graph indicate the occurrence of sea states (in number of hours per year).

The SH7 site is located approximately $1.2 \mathrm{~km}$ from the city of Marsala. At this site, highly energetic waves come from the direction in the range of $260-290^{\circ} \mathrm{N}$, and less energetic waves come from the direction of $180-210^{\circ} \mathrm{N}$. The wave energy flux is slightly greater than $7 \mathrm{~kW} \mathrm{~m}^{-1}$ for the winter months, whereas for the summer months, a reduction to $1.29 \mathrm{~kW} \mathrm{~m}^{-1}$ is observed.
The SH8 site is located approximately $9 \mathrm{~km}$ from the city of Mazara del Vallo. The wave energy flux is approximately $5.4 \mathrm{~kW} \mathrm{~m}^{-1}$. The wave energy is concentrated in the range of 5-9 $\mathrm{s}$ with respect to $T_{\mathrm{e}}$ and $1-4 \mathrm{~m}$ with respect to $H_{m 0}$, with an annual frequency of $27.84 \%$ (approximately 101.6 days year $^{-1}$ ). The percent of "no calm" is approximately $66.77 \%$. The dominant directions are included in the sector at $270-300^{\circ} \mathrm{N}$, with a frequency of $40.35 \%$. The wave 


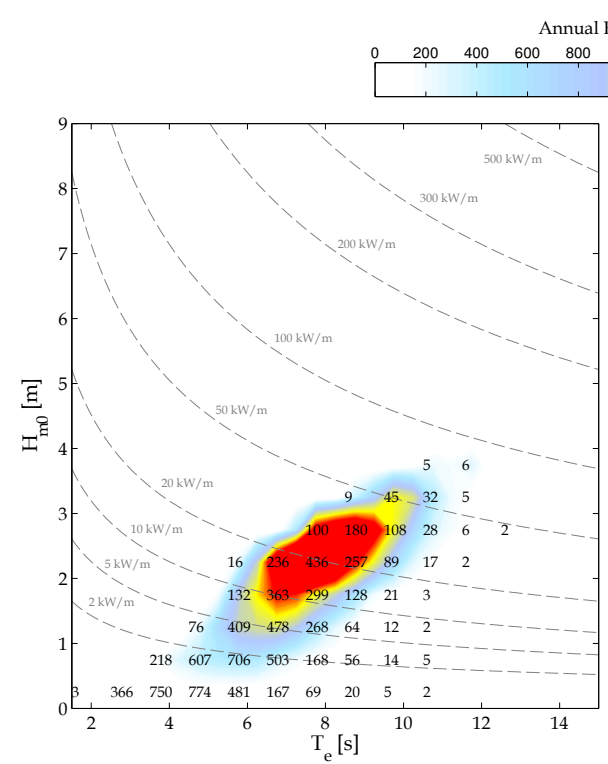

Anual Energy $[\mathrm{kWh} / \mathrm{m}]$

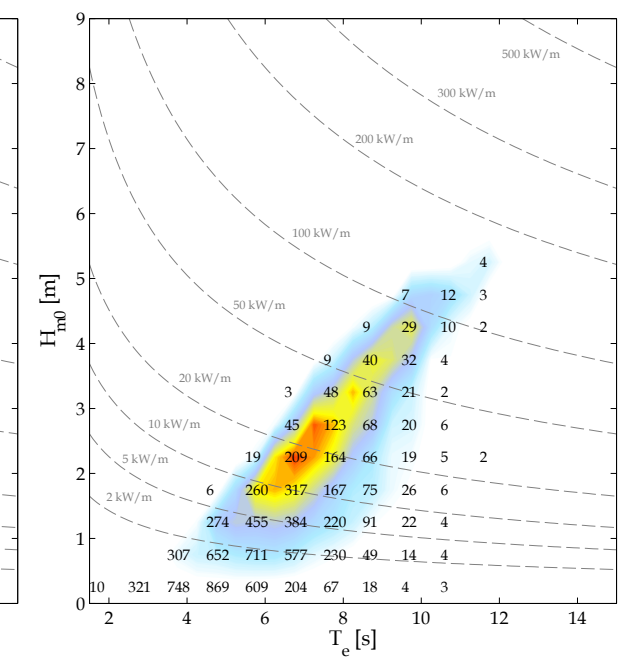

Figure 14. Characterisation of the yearly average wave energy in terms of $H_{m 0}$ and $T_{\mathrm{e}}$ : on the left site HS5 and on the right site HS6. The colour scale represents annual energy per metre of wave front (in $\mathrm{MWh} \mathrm{m}^{-1}$ ). The numbers within the graph indicate the occurrence of sea states (in number of hours per year).
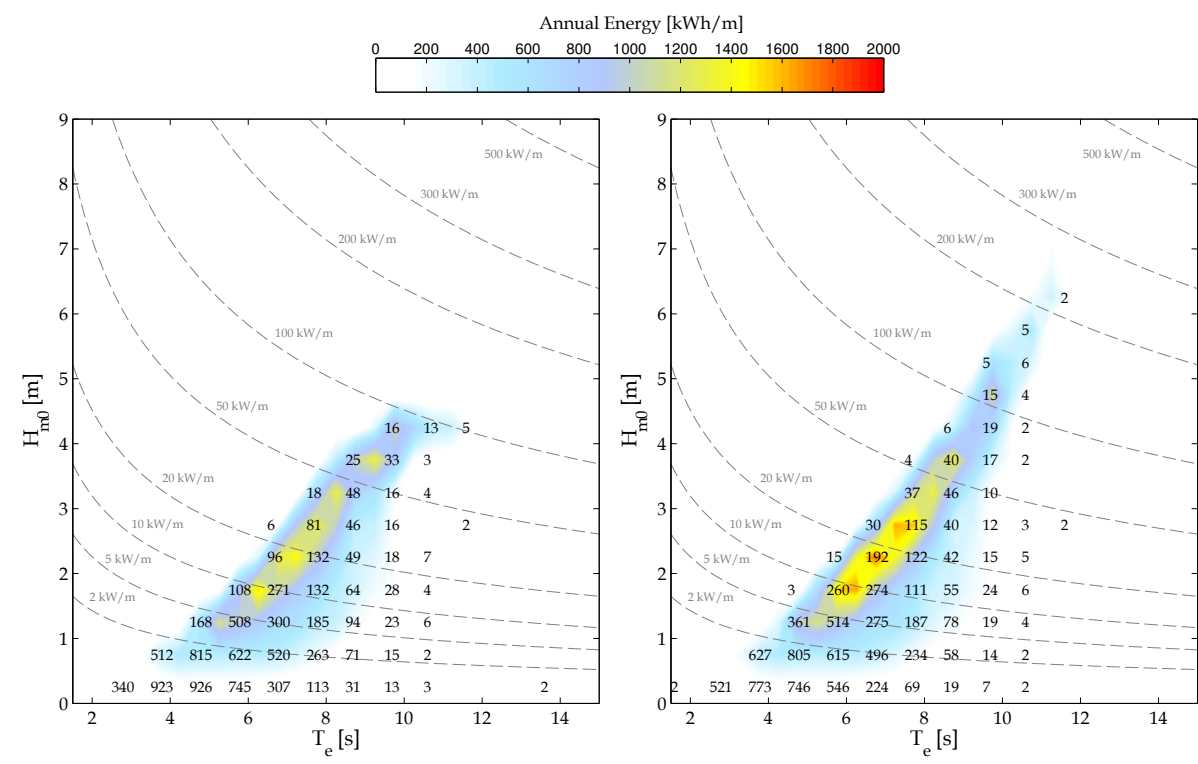

Figure 15. Characterisation of the yearly average wave energy in terms of $H_{m 0}$ and $T_{\mathrm{e}}$ : on the left site HS7 and on the right site HS8. The colour scale represents annual energy per metre of wave front (in $\mathrm{MWh} \mathrm{m}^{-1}$ ). The numbers within the graph indicate the occurrence of sea states (in number of hours per year).

energy flux is slightly greater than $9.5 \mathrm{~kW} \mathrm{~m}^{-1}$ for the winter months, whereas for the summer months a reduction to $1.51 \mathrm{~kW} \mathrm{~m}^{-1}$ is observed.

\section{Discussion and conclusions}

The characterisation of hotspots is important for the appropriate location of a WEC farm, especially in the Mediter- ranean Sea which includes sites where a wave energy concentration can be observed due to wave transformation.

In the present study, the potential wave energy along the coasts of Sicily was investigated to identify possible sites for the installation of wave farms near the coast. The analysis was based on wave and wind data obtained from the forecast centre ECMWF, which covers a period of 14 years (19992012) with a time resolution of $6 \mathrm{~h}$. The wave data were prop- 

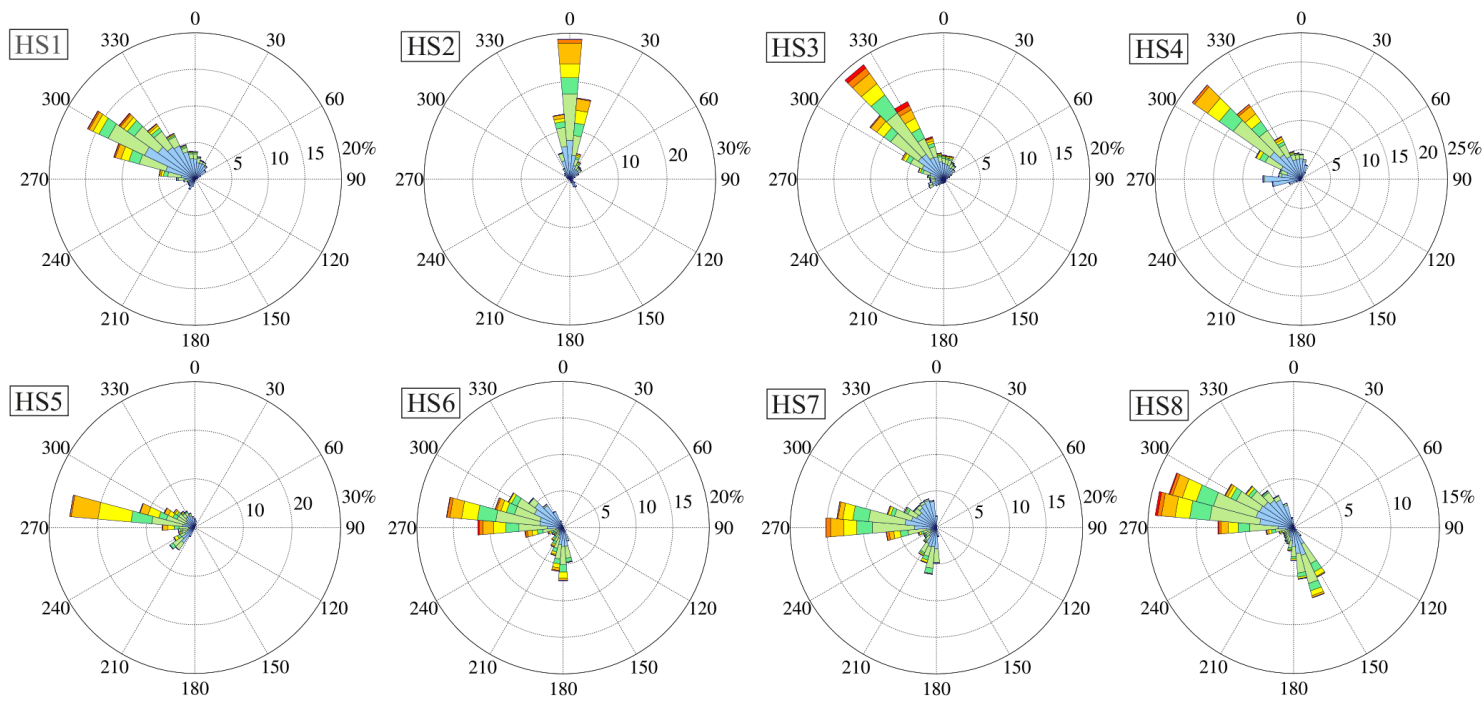

Wave Power $[\mathrm{kW} / \mathrm{m}]$

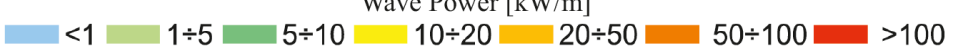

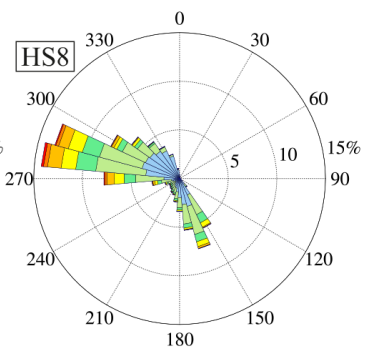

Figure 16. Wave power climate for the sites selected.

agated using the SWAN model, which allows wave propagation to be studied by taking into account several phenomena such as whitecapping, nonlinear wave-wave interactions, refraction, diffraction and wave regeneration due to wind. To validate the model, the significant wave height output was compared to data from several satellites. Good agreement was found between the two data sets.

The obtained results of the wave energy flux showed that the most energetic areas are located on the western side of Sicily and in the Strait of Sicily. The offshore values of the observed energy flux are close to $8 \mathrm{~kW} \mathrm{~m}^{-1}$ on the western side, with a reduction in the Strait of Sicily to $4-6 \mathrm{~kW} \mathrm{~m}^{-1}$. The wave energy flux is further reduced to $2-3 \mathrm{~kW} \mathrm{~m}^{-1}$ on the north and east sides of Sicily. Comparing the wave energy estimates along the bathymetry at $-10,-20$ and $-50 \mathrm{~m}$, eight hotspots were identified (Fig. 11 represents the locations of the sites). In particular, the HS3 site (near Capo San Vito) is the most energetic, although the analysis of the energy distribution showed that wave energy flux is determined by events that have high energy but a low annual frequency. Instead, the SH5 site (near the island of Favignana) is characterised by an average wave power of less than HS3, but the energy is concentrated in a limited range of $H_{m 0}$ and $T_{\mathrm{e}}$ with an annual frequency of $25.97 \%$. The concentrated energy flux in the limited range of $H_{m 0}$ and $T_{\mathrm{e}}$ and within a limited sector is an important characteristic for the productivity of WECs. Indeed, the devices are generally designed to guarantee good performances in average climates. Therefore, smaller variations in wave climate compared to the design conditions correspond to greater production of energy from the device. A similar energy distribution was observed for the HS2 (near Capo San Vito) and HS4 (near the Trapani port) sites, although they exhibit lower average energy than the HS5 site. The HS1 site (near the Terrasini port) does not generate sufficient energy to ensure an economic payback over a reasonable period of time. The percentage of calm events (significant wave height less $0.5 \mathrm{~m}$ ) is greater than $50 \%$ and the annual average wave energy is approximately $3.3 \mathrm{~kW} \mathrm{~m}^{-1}$. For the HS6 (near the island of Marettimo), HS7 (near the Marsala port) and HS8 (near the Mazara del Vallo port) sites, the wave energy arrives not only from the dominant direction, as observed for the other sites, but also from secondary directions. Therefore, to better exploit wave energy, it is best to utilise fixed unidirectional devices at the HS2-HS5 sites, whereas for the latter three sites it is more convenient to use directional devices.

These analyses show that profitable WECs could be realised at various sites around Sicily. However, currently, the majority of devices are designed for areas with high wave energy. 
Appendix A: Parameters for comparison between the model and buoy data

The parameters used for comparison of the different data sets are defined by the following relationships:

bias $=\frac{1}{n} \cdot \sum_{i=1}^{N}\left(y_{i}-x_{i}\right)$,

$\mathrm{RMSE}=\sqrt{\frac{1}{n-1} \cdot \sum_{i=1}^{N}\left(y_{i}-x_{i}\right)^{2}}$,

$\mathrm{si}=\frac{\mathrm{RMSE}}{\frac{1}{n} \cdot \sum_{i=1}^{N}\left(y_{i}\right)}$,

$d=1-\frac{\sum_{i=1}^{N}\left(y_{i}-x_{i}\right)^{2}}{\sum_{i=1}^{N}\left(\left|y_{i}^{\prime}\right|-\left|x_{i}{ }^{\prime}\right|\right)^{2}}$,

$R=\frac{\sum_{i=1}^{N}\left(x_{i}-\bar{x}\right)\left(y_{i}-\bar{y}\right)}{\sqrt{\sum_{i=1}^{N}\left(x_{i}-\bar{x}\right)^{2}} \sqrt{\sum_{i=1}^{N}\left(y_{i}-\bar{y}\right)^{2}}}$,

where $x_{i}$ and $y_{i}$ are the compared data sets, $\left|x_{i}{ }^{\prime}\right|=\left|x_{i}-\bar{x}\right|$ and $\left|y_{i}{ }^{\prime}\right|=\left|y_{i}-\bar{y}\right|$, where $\bar{x}$ and $\bar{y}$ are the averages of the compared data sets. 
Acknowledgements. This work has been partially funded by the project PON02_000153_2939551 - Development of innovative technologies for energy saving and environmental sustainability of shipyards and harbour areas SEAPORT - and by the EC-funded project HYDRALAB IV (contract no. 261520). The work also was partially supported by the EC FP7 Marie Curie Actions People, Contract PIRSES-GA-2011-295162 - ENVICOP project (Environmentally Friendly Coastal Protection in a Changing Climate) - and by the RITMARE Flagship Project (National Research Programmes funded by the Italian Ministry of Universities and Research). The ECMWF data was provided by the MARS archive with the authorisation of the Italian Air Force.

Edited by: S. Carniel

\section{References}

Azzellino, A., Conley, D., Vicinanza, D., and Kofoed, J.: Marine renewable energies: perspectives and implications for marine ecosystems, The Scientific World Journal, 2013, 547563, doi:10.1155/2013/547563, 2013a.

Azzellino, A., Ferrante, V., Kofoed, J. P., Lanfredi, C., and Vicinanza, D.: Optimal siting of offshore wind-power combined with wave energy through a marine spatial planning approach, International Journal of Marine Energy, 3-4, e11-e25, doi:10.1016/j.ijome.2013.11.008, Special Issue - Selected Papers - \{EWTEC2013\}, 2013b.

Barbariol, F., Benetazzo, A., Carniel, S., and Sclavo, M.: Improving the assessment of wave energy resources by means of coupled wave-ocean numerical modeling, Renew. Energ., 60, 462-471, doi:10.1016/j.renene.2013.05.043, 2013.

Booij, N., Ris, R., and Holthuijsen, L.: A third-generation wave model for coastal regions 1. Model description and validation, J. Geophys. Res.-Oceans, 104, 7649-7666, doi:10.1029/98JC02622, 1999.

Cavaleri, L.: Wave modeling-missing the peaks, J. Phys. Oceanogr., 39, 2757-2778, doi:10.1175/2009JPO4067.1, 2009.

Cavaleri, L. and Bertotti, L.: Accuracy of the modelled wind and wave fields in enclosed seas, Tellus A, 56, 167-175, doi:10.1111/j.1600-0870.2004.00042.x, 2004.

Falnes, J.: A review of wave-energy extraction, Mar. Struct., 20, 185-201, doi:10.1016/j.marstruc.2007.09.001, 2007.

GEBCO: General Bathymetric Chart of the Oceans (GEBCO), The GEBCO08 Grid, Tech. rep., General Bathymetric Chart of the Oceans, 1999.
Hasselmann, K., Hasselmann, S., Bauer, E., Janssen, P., Komen, G., Bertotti, L., Lionello, P., Guillaume, A., Cardone, V., Greenwood, J., Reistad, M., Zambresky, L., and Ewing, J.: The WAM model - a third generation ocean wave prediction model, J. Phys. Oceanogr., 18, 1775-1810, doi:10.1175/15200485(1988)018<1775:TWMTGO>2.0.CO;2, 1988.

IEA: Renewable energy, Market Analysis and Forecasts to 2020 Medium-Term Market Report EXECUTIVE SUMMARY, Tech. rep., Intertnational Energy Agency, 2014.

Iglesias, G. and Carballo, R.: Wave energy resource in the Estaca de Bares area (Spain), Renew. Energ., 35, 1574-1584, doi:10.1016/j.renene.2009.10.019, Special Section: $\{$ IST $\}$ National Conference 2009, 2010a.

Iglesias, G. and Carballo, R.: Wave energy and nearshore hot spots: the case of the $\{\mathrm{SE}\}$ Bay of Biscay, Renew. Energ., 35, 24902500, doi:10.1016/j.renene.2010.03.016, 2010 b.

Iuppa, C., Cavallaro, L., and Foti, E. (Eds.): Potential wave energy along the coasts of Sicily (Italy), 3rd IAHR Europe Congress, Book of Proceedings, 2014.

Kallesøe, B., Dixen, F. H., Hansen, H., and Køhler, A. (Eds.): Prototype test and modeling of a combined wave and wind energy conversion system, 8th European Wave and Tidal Energy Conference, 2009.

Liberti, L., Carillo, A., and Sannino, G.: Wave energy resource assessment in the Mediterranean, the Italian perspective, Renew. Energ., 50, 938-949, doi:10.1016/j.renene.2012.08.023, 2013.

Queffeulou, P.: Long-term validation of wave height measurements from altimeters, Mar. Geod., 27, 495-510, doi:10.1080/01490410490883478, 2004.

Queffeulou, P. and Croizé-Fillo, D.: Global altimeter SWH data set, version 10, Tech. rep., IFREMER, 2013.

Tolman, H. and Chalikov, D.: Source terms in a third-generation wind wave model, J. Phys. Oceanogr., 26, 2497-2518, doi:10.1175/1520-0485(1996)026<2497:STIATG>2.0.CO;2, 1996.

Tucker, M.: Nearshore waveheight during storms, Coast. Eng., 24, 111-136, doi:10.1016/0378-3839(94)90029-9, 1994.

Vicinanza, D., Cappietti, L., Ferrante, V., and Contestabile, P.: Estimation of the wave energy in the Italian offshore, J. Coastal Res. 64, 613-617, 2011.

Vicinanza, D., Contestabile, P., Nørgaard, J. Q. H., and Andersen, T. L.: Innovative rubble mound breakwaters for overtopping wave energy conversion, Coast. Eng., 88, 154-170, doi:10.1016/j.coastaleng.2014.02.004, 2014.

Willmott, C.: Some comments on the evaluation of model performance, B. Am. Meteorol. Soc., 63, 1309-1313, doi:10.1175/1520-0477(1982)063<1309:SCOTEO>2.0.CO;2, 1982. 